\title{
Transforming a single-use Spaceport to multi-use
}

\author{
Hector. N. Delgado \\ Mail Code: NE-D \\ NASA John F. Kennedy Space Center, Florida, 32899 USA \\ Phone: 1-321-867-9295 \\ Hector.N.Delgado@nasa.gov
}

\begin{abstract}
The end of the Space Shuttle program brought new challenges as well as new opportunities to the John F. Kennedy Space Center. The challenge is to engineer a more flexible Spaceport to be capable of supporting manufacturing, assembly, testing, processing and launch operations for multiple spacecrafts and launch vehicle configurations. The new spaceport must support multiple commercial as well as government entities while leveraging existing infrastructure to the greatest extent possible.

This paper addresses key engineering challenges during Spaceport design and development and will look at possible engineering solutions while considering reusability of legacy systems and infrastructure adaptability with emphasis on flexibility and reduction of operating cost.
\end{abstract}

